\title{
Exercise and mental health: what did we learn in the last 20 years?
}

\author{
Andrea Camaz Deslandes* \\ Neuroscience of Exercise Lab (LaNEx), Psychiatric Institute, Universidade Federal do Rio de Janeiro, Rio de Janeiro, Brazil \\ *Correspondence: lanexugf@gmail.com \\ Edited and reviewed by: \\ Felipe Schuch, Hospital de Clínicas de Porto Alegre, Brazil
}

Keywords: exercise, depression, neurogenesis, mental health, mental disorders

Although an active lifestyle has always been recognized as the best way to achieve health in the entire history of civilization, over the last two decades, the concept of exercise as medicine (1), or as a preventive method, became increasingly accepted. Some authors consider physical exercise as a "polypill" that, besides many benefits in preventing and treating several diseases, has the advantage of not generating adverse responses and of being a low cost alternative compared to drugs, surgeries, and hospitalizations (2). Researches about the protective effects of physical training and of an active lifestyle in the prevention of metabolic and cardiovascular diseases are not altogether new. However, greater attention is being given to the effects of exercise upon the brain, cognitive function, and behavior (3-5). Since the classic study conducted by Van Praag (6), where the authors showed for the first time that animals submitted to voluntary exercise had an increased neurogenesis, exercise has been investigated as a potential enhancer of cognitive and behavioral functions. Fifteen years later, studies on animal models continue to unravel various neurobiological mechanisms associated with exercise. In another classic study on the neurobiology of exercise, Dishman et al. (3) showed us several ways to explain the prevention and treatment of diseases (including mental diseases) through physical exercise.

However, randomized control trials continue to progress slowly. Studies have shown behavioral, cognitive, and functional improvements in patients who are undergoing physical training, but few have focused on investigating possible neurobiological mechanisms in humans. A better functional capacity and an active lifestyle have been associated with a lower risk of developing neurodegenerative disorders (7), and mood and anxiety disorders (811 ), but the physiological mechanisms are unclear. Works investigating the acute and chronic effects of exercise on cognitive function show promising results in different age groups (children, youth, adults, and seniors) (12-15). However, many questions remain unanswered, such as the right amount of exercise to improve this protective response, the appropriate type, intensity and duration of the training session, and the minimum weekly frequency and duration of benefits after cessation of activity. It is time to think about what we have learned so far and what we still need to understand about exercise and mental health.

\section{WHAT DO WE KNOW SO FAR?}

\section{HUMANS ARE MADE TO MOVE}

In the evolutionary history of human species, several systems need to move to stay healthy and survive (16). Muscles, bones, and even the brain are made of billions of cells that need stimulation for biomolecular signals to occur. Our hearts need to keep beating in order to pump oxygen and energy substrate throughout the entire human body, as much as the skeletal muscles need to be constantly stimulated to synthesize specific myokines that are necessary to maintain health and metabolic activities $(17,18)$. The extracellular signaling, through neurotransmitters, hormones, growth factors, cytokines, or even mechanical forces, has to constantly occur in order to inhibit the cellular apoptosis and maintain mitochondrial activity and protein synthesis (2). Physical training can promote this stimulus from the brain to the muscle, or vice versa. Although there is a vast literature on the mechanisms of exercise on physical and mental health, one of the main hypotheses is associated with mitochondria, a critical organelle for the survival and the appropriate functioning of cells and, consequently, of every system.

Mitochondrion is a strong candidate to mediate the relationship between exercise and the reduced risk of frailty and mental illness. It is our powerhouse, generating the chemical energy (ATP) necessary for cell survival. On the other hand, it is also responsible for the production of reactive oxidative species (ROS) related to inflammatory processes, aging, and several metabolic and mental diseases (19, 20). According to Radak (21-23), although exercise is associated with acute increases of ROS, chronic alterations related to adaptation to this kind of stimulus contribute to an increased antioxidant enzymes activity. Moreover, exercise promotes mitochondrial biogenesis and makes enzymes more efficient (oxidant and antioxidant), contributing to improved metabolism, function, and cell survival throughout the entire body $(24,25)$.

Metabolism and protein synthesis maintenance is another important exercise mechanism for promoting health. Inducing the production of trophic factors (such as BDNF, IGF-I, VEGF, GNF) and neurotransmitters (such as dopamine, serotonin, and norepinephrine) contributes to various brain responses, for instance, increased neurogenesis, angiogenesis, synaptogenesis, and inhibition of caspases (3-6, 26-29). Moreover, the increase of neurotropic factors induces presynaptic signals associated with increased release of neurotransmitters in the synaptic cleft and the resulting growth in synaptic transmission and neuroplasticity (30-34). BDNF also contributes to increased long-term potential (LTP) (35-37). During exercise, besides 
activating motor circuit areas, associative and limbic areas also benefit from the increased synthesis and release of dopamine. Moreover, the activation of opioid and cannabinoid systems contributes to acute anxiolytic response to exercise (30-34, 38).

\section{WHAT SHOULD WE DO? TYPE, FREOUENCY, DURATION, AND INTENSITY OF EXERCISE: IS MORE NECESSARILY BETTER?}

Although many neurobiological mechanisms justify the use of exercise in treating mental illness, it is uncertain how we may prescribe this "polypill." For example, we know that both aerobic and strength training contribute to improve cognitive function, especially the executive function (13$15,39)$, and to reduce depressive symptoms $(4,40,41)$. It is also known that this improvement may occur through distinct or redundant neurobiological pathways, such as increased neurotrophins. However, there are currently no evidences indicating if certain exercises, e.g., stretching or swimming, would also be favorable. Moreover, it is known that aerobic exercise at moderate intensity $(41,42)$ contributes to reducing depression and increasing the rate of remission and response among elderly patients. However, it is unclear if these patients would benefit more from making high-intensity interval workouts. Studies indicate that patients with neurodegenerative diseases such as dementia benefit from aerobic exercises. Recently, our laboratory found that elderly people with Alzheimer's disease have better response to treatment when performing a 30-min walk on the treadmill at a moderate intensity (43). There is only one study submitting patients with $\mathrm{AD}$ to a strength training protocol, which found a favorable response in strength and functional capacity. However, the authors did not investigate clinical issues associated with the disease (44). Therefore, it is not possible to indicate this type of exercise for better response to $\mathrm{AD}$ treatment.

\section{CONCLUSION}

Although there are many neurobiological evidences indicating exercise programs to reduce symptoms and increase treatment response of several mental disorders, there is still a long way to go in clinical randomized control trials. Authors in this area need to make an effort to find evidences that may help to determine a more adequate prescription of exercise (type, duration, frequency, and intensity) for each diagnosis of mental illness.

\section{REFERENCES}

1. Sallis RE. Exercise is medicine and physicians need to prescribe it! Br J Sports Med (2009) 43:3-4. doi:10.1136/bjsm.2008.054825

2. Fiuza-Luces C, Garatachea N, Berger NA, Lucia A. Exercise is the real polypill. Physiology (2013) 28:330-58. doi:10.1152/physiol.00019.2013

3. Dishman RK, Berthoud H-R, Booth FW, Cotman CW, Edgerton VR, Fleshner MR, et al. Neurobiology of exercise. Obesity (2006) 14:345-56. doi:10.1038/oby.2006.46

4. Deslandes A, Moraes H, Ferreira C, Veiga H, Silveira $H$, Mouta $R$, et al. Exercise and mental health: many reasons to move. Neuropsychobiology (2009) 59:191-8. doi:10.1159/000223730

5. Matta Mello Portugal E, Cevada T, Sobral Monteiro R Jr, Teixeira Guimarães T, da Cruz Rubini E, Lattari E, et al. Neuroscience of exercise: from neurobiology mechanisms to mental health. Neuropsychobiology (2013) 68:1-14. doi:10.1159/000350946

6. Van Praag H, Kempermann G, Gage FH. Running increases cell proliferation and neurogenesis in the adult mouse dentate gyrus. Nat Neurosci (1999) 2:266-70. doi:10.1038/6368

7. Hamer M, Chida Y. Physical activity and risk of neurodegenerative disease: a systematic review of prospective evidence. Psychol Med (2009) 39:3. doi:10.1017/S0033291708003681

8. Bonnet F, Irving K, Terra J-L, Nony P, Berthezène F, Moulin P. Anxiety and depression are associated with unhealthy lifestyle in patients at risk of cardiovascular disease. Atherosclerosis (2005) 178:339-44. doi:10.1016/j.atherosclerosis.2004.08. 035

9. Sjösten N, Kivelä S-L. The effects of physical exercise on depressive symptoms among the aged: a systematic review. Int J Geriatr Psychiatry (2006) 21:410-8. doi:10.1002/gps.1494

10. Martinsen EW. Physical activity in the prevention and treatment of anxiety and depression. Nord J Psychiatry (2008) 62:25-9. doi:10.1080/ 08039480802315640

11. Barcelos-Ferreira R, Pinto JA Jr, Nakano EY, Steffens DC, Litvoc J, Bottino C. Clinically significant depressive symptoms and associated factors in community elderly subjects from Sao Paulo, Brazil. Am J Geriatr Psychiatry (2009) 17:582-90. doi:10.1097/JGP.0b013e3181a76ddc

12. Colcombe SJ, Kramer AF, Erickson KI, Scalf P, McAuley E, Cohen NJ, et al. Cardiovascular fitness, cortical plasticity, and aging. Proc Natl Acad Sci U S A (2004) 101:3316-21. doi:10.1073/pnas. 0400266101

13. Cassilhas RC, Viana VA, Grassmann V, Santos RT, Santos RF, Tufik S, et al. The impact of resistance exercise on the cognitive function of the elderly. Med Sci Sports Exerc (2007) 39:1401. doi:10.1249/ mss.0b013e318060111f
14. Hillman $\mathrm{CH}$, Erickson KI, Kramer AF. Be smart, exercise your heart: exercise effects on brain and cognition. Nat Rev Neurosci (2008) 9:58-65. doi: $10.1038 / \mathrm{nrn} 2298$

15. Diamond A, Lee K. Interventions shown to aid executive function development in children 4 to 12 years old. Science (2011) 333:959-64. doi:10.1126/ science. 1204529

16. Vaynman S, Gomez-Pinilla F. Revenge of the "sit": how lifestyle impacts neuronal and cognitive health through molecular systems that interface energy metabolism with neuronal plasticity. J NeurosciRes (2006) 84:699-715. doi:10.1002/jnr.20979

17. Nieman DC, Pedersen BK. Exercise and immune function. Sports Med (1999) 27:73-80. doi:10. 2165/00007256-199927020-00001

18. Pedersen BK, Steensberg A, Fischer C, Keller C, Keller P, Plomgaard P, et al. Searching for the exercise factor: is IL-6 a candidate? J Muscle Res Cell Motil (2003) 24:113-9. doi:10.1023/A: 1026070911202

19. Hiona A, Leeuwenburgh C. The role of mitochondrial DNA mutations in aging and sarcopenia: implications for the mitochondrial vicious cycle theory of aging. Exp Gerontol (2008) 43:24-33. doi:10.1016/j.exger.2007.10.001

20. Glass CK, Saijo K, Winner B, Marchetto MC, Gage $\mathrm{FH}$. Mechanisms underlying inflammation in neurodegeneration. Cell (2010) 140:918-34. doi:10. 1016/j.cell.2010.02.016

21. Radak Z, Taylor AW, Ohno H, Goto S. Adaptation to exercise-induced oxidative stress: from muscle to brain. Exerc Immunol Rev (2000) 7:90-107.

22. Radak Z, Chung HY, Goto S. Exercise and hormesis: oxidative stress-related adaptation for successful aging. Biogerontology (2005) 6:71-5. doi:10. 1007/s10522-004-7386-7

23. Radak Z, Chung HY, Goto S. Systemic adaptation to oxidative challenge induced by regular exercise. Free Radic Biol Med (2008) 44:153-9. doi:10.1016/j.freeradbiomed.2007.01.029

24. Marzetti E, Lawler JM, Hiona A, Manini T, Seo AY, Leeuwenburgh C. Modulation of age-induced apoptotic signaling and cellular remodeling by exercise and calorie restriction in skeletal muscle. Free Radic Biol Med (2008) 44:160-8. doi:10.1016/ j.freeradbiomed.2007.05.028

25. Iversen N, Krustrup P, Rasmussen HN, Rasmussen UF, Saltin B, Pilegaard H. Mitochondrial biogenesis and angiogenesis in skeletal muscle of the elderly. Exp Gerontol (2011) 46:670-8. doi:10.1016/j.exger. 2011.03.004

26. Gustafsson T, Puntschart A, Kaijser L, Jansson E, Sundberg CJ. Exercise-induced expression of angiogenesis-related transcription and growth factors in human skeletal muscle. Am J Physiol Heart Circ Physiol (1999) 276:H679-85.

27. Van Praag H, Shubert T, Zhao C, Gage FH. Exercise enhances learning and hippocampal neurogenesis in aged mice. J Neurosci (2005) 25:8680-5. doi:10.1523/JNEUROSCI.1731-05.2005

28. Cotman CW, Berchtold NC, Christie L-A. Exercise builds brain health: key roles of growth factor cascades and inflammation. Trends Neurosci (2007) 30:464-72. doi:10.1016/j.tins.2007.06.011

29. Van Praag H. Neurogenesis and exercise: past and future directions. Neuromolecular Med (2008) 10:128-40. doi:10.1007/s12017-008-8028-z 
30. Sparling PB, Giuffrida A, Piomelli D, Rosskopf L, Dietrich A. Exercise activates the endocannabinoid system. Neuroreport (2003) 14:2209-11. doi: 10.1097/00001756-200312020-00015

31. Dietrich A, McDaniel WF. Endocannabinoids and exercise. Br J Sports Med (2004) 38:536-41. doi:10. 1136/bjsm.2004.011718

32. Boecker H, Sprenger T, Spilker ME, Henriksen G, Koppenhoefer M, Wagner KJ, et al. The runner's high: opioidergic mechanisms in the human brain. Cereb Cortex (2008) 18:2523-31. doi:10. 1093/cercor/bhn013

33. Dishman RK, O'Connor PJ. Lessons in exercise neurobiology: the case of endorphins. Ment Health Phys Act (2009) 2:4-9. doi:10.1016/j.mhpa.2009. 01.002

34. Raichlen DA, Foster AD, Gerdeman GL, Seillier A, Giuffrida A. Wired to run: exercise-induced endocannabinoid signaling in humans and cursorial mammals with implications for the "runner"s high'. J Exp Biol (2012) 215:1331-6. doi:10.1242/ jeb.063677

35. Vaynman S, Ying Z, Gomez-Pinilla F. Hippocampal BDNF mediates the efficacy of exercise on synaptic plasticity and cognition. Eur J Neurosci (2004) 20:2580-90. doi:10.1111/j.1460-9568.2004. 03720.x

36. Bekinschtein P, Oomen CA, Saksida LM, Bussey TJ. Effects of environmental enrichment and voluntary exercise on neurogenesis, learning and memory, and pattern separation: BDNF as a critical variable? Semin Cell Dev Biol (2014):536-42. doi:10.1016/j.semcdb.2011.07.002
Available from: http://www.sciencedirect.com/ science/article/pii/S1084952111000887

37. Bechara RG, Lyne R, Kelly ÁM. BDNFstimulated intracellular signalling mechanisms underlie exercise-induced improvement in spatial memory in the male Wistar rat. Behav Brain Res (2013). doi:10.1016/j.bbr.2013.11.015 Available from: http://www.sciencedirect.com/science/ article/pii/S016643281300692X

38. Sforzo GA. Opioids and exercise. Sports Med (1989) 7:109-24. doi:10.2165/00007256198907020-00003

39. Colcombe S, Kramer AF. Fitness effects on the cognitive function of older adults a meta-analytic study. Psychol Sci (2003) 14:125-30. doi:10.1111/ 1467-9280.t01-1-01430

40. Silveira H, Deslandes AC, de Moraes H, Mouta R, Ribeiro P, Piedade R, et al. Effects of exercise on electroencephalographic mean frequency in depressed elderly subjects. Neuropsychobiology (2010) 61:141-7. doi:10.1159/000279304

41. Silveira H, Moraes H, Oliveira N, Coutinho ESF, Laks J, Deslandes A. Physical exercise and clinically depressed patients: a systematic review and metaanalysis. Neuropsychobiology (2013) 67:61-8. doi: $10.1159 / 000345160$

42. Cassilhas RC, Antunes HKM, Tufik S, de Mello MT. Mood, anxiety, and serum IGF-1 in elderly men given 24 weeks of high resistance exercise 1, 2 . Percept Mot Skills (2010) 110:265-76. doi:10.2466/ pms.110.1.265-276

43. Arcoverde C, Deslandes A, Moraes H, Almeida C, Araujo NB, de Vasques PE, et al. Treadmill training as an augmentation treatment for Alzheimer's disease: a pilot randomized controlled study. Arq Neuropsiquiatr (2014) 72:190-6. doi:10.1590/0004282X20130231

44. Hauer K, Schwenk M, Zieschang T, Essig M, Becker C, Oster P. Physical training improves motor performance in people with dementia: a randomized controlled trial. J Am Geriatr Soc (2012) 60:8-15. doi:10.1111/j.1532-5415.2011.03778.x

Conflict of Interest Statement: The author declares that the research was conducted in the absence of any commercial or financial relationships that could be construed as a potential conflict of interest.

Received: 15 May 2014; accepted: 23 May 2014; published online: 13 June 2014

Citation: Deslandes AC (2014) Exercise and mental health: what did we learn in the last 20 years? Front. Psychiatry 5:66. doi: 10.3389/fpsyt.2014.00066

This article was submitted to Affective Disorders and Psychosomatic Research, a section of the journal Frontiers in Psychiatry.

Copyright (C) 2014 Deslandes. This is an open-access article distributed under the terms of the Creative Commons Attribution License (CC BY). The use, distribution or reproduction in other forums is permitted, provided the original author(s) or licensor are credited and that the original publication in this journal is cited, in accordance with accepted academic practice. No use, distribution or reproduction is permitted which does not comply with these terms. 